\title{
0733. Impact of endotoxin challenge on disseminated intravascular coagulation in obese minipigs
}

\author{
T Duburcq ${ }^{1,2,3^{*}}$, A Tournoys $^{4}$, F Pattou $^{1,2}$, T Hubert $^{1,2}$, V Gmyr $r^{1,2}$, L Quintane $^{1,2}$, R Favory $^{3}$, J Mangalaboyi ${ }^{3}$, \\ M Jourdain ${ }^{1,2,3}$
}

From ESICM LIVES 2014

Barcelona, Spain. 27 September - 1 October 2014

\section{Introduction}

An early activation of coagulation and fibrinolysis occurs during sepsis and results in a marked increase of thrombin and fibrin formation, leading to the syndrome of disseminated intravascular coagulation (DIC). DIC is a strong predictor of death and multiple organ failure in patients with septic shock [1]. Obesity has been demonstrated to be a hypercoagulable [2] and hypofibrinolytic [3] state but its impact on coagulation and fibrinolysis during sepsis has never been studied.

\section{Objectives}

In this study, we aimed to determine if obesity impairs DIC in an acute endotoxic shock using minipigs.

\section{Methods}

This was a prospective, comparative and experimental study, approved by the Animal Ethics Committee. Pigs were chosen as a clinically relevant species, resembling to humans in coagulation reactions. Four groups of five "Yucatan" minipigs were studied: lean and obese control groups, lean LPS group receiving Escherichia Coli endotoxin (LPS) and obese LPS group receiving the same endotoxin dose. We measured standard coagulation parameters [prothrombin time (PT), platelet count and fibrinogen levels], thrombin-antithrombin complex (TAT), tissue plasminogen activator (t-PA) and plasminogen activator inhibitor-1 (PAI-1). All measurements were performed at baseline and at 30, 60, 90, 150 and 300 minutes. Results were given as median with 25-75 interquartile ranges.

\section{Results}

At baseline, platelet count (477 [428-532] vs. 381 [307442] G/l; $\mathrm{p}=0.005)$ and fibrinogen levels (4.6 [3.8-5.2] vs. 2 $[1.8-2.9] \mathrm{g} / \mathrm{l} ; \mathrm{p}<0.001)$ were significantly higher whereas prothrombin time (80 [76-92] vs. 96 [89-100] \%; $p=0.01)$ was significantly lower in obese pigs compared to lean pigs. Control groups remained stable during the studyperiod. In LPS groups, administration of endotoxin resulted in a typical hypokinetic shock with DIC. The decrease in coagulation parameters (PT, platelet count and fibrinogen levels) and the increase in TAT complex (581 [382-1057] vs. 247 [125-369] $\mu \mathrm{g} / \mathrm{ml}$ at $150 \mathrm{~min} ; \mathrm{p}=0.03$ ) were significantly more important in obese LPS group compared to lean LPS group. Concerning the fibrinolytic reaction, we found a more important increase of PAI-1 in obese LPS group at $300 \mathrm{~min}$ (481 [365-617] $\mathrm{ng} / \mathrm{ml}$ vs. 355 [209-660] ng/ml; $\mathrm{p}=0.66$ ) without reaching statistical significance. Nevertheless, the increase of t-PA was significantly lower in obese LPS group compared to lean LPS group at $90 \mathrm{~min}(10$ [8-17] vs. 5 [2-9] ng/ml; $\mathrm{p}=0.04)$.

\section{Conclusions}

In our model of endotoxic shock, obese pigs developed a more severe disseminated intravascular coagulation with a more serious procoagulant response.

\section{Authors' details \\ ${ }^{1}$ INSERM U859, Lille, France. ²European Genomic Institute for Diabetes (EGID), Lille, France. ${ }^{3}$ Pole de Réanimation CHRU, Lille, France. ${ }^{4}$ Centre de Biologie Pathologie CHRU, Lille, France.}

Published: 26 September 2014 


\section{References}

1. Angstwurm MWA, et al: Crit Care Med 2006, 34(2):314-320, févr.

2. Stoppa-Vaucher S, et al: Obes Silver Spring Md 2012, 20(8):1662-1668, août.

3. Semeraro F, et al: Thromb Haemost 2012, 108(2):311-317, août.

doi:10.1186/2197-425X-2-S1-P55

Cite this article as: Duburcq et al:: 0733. Impact of endotoxin challenge on disseminated intravascular coagulation in obese minipigs. Intensive Care Medicine Experimental 2014 2(Suppl 1):P55.

\section{Submit your manuscript to a SpringerOpen ${ }^{\circ}$ journal and benefit from:}

- Convenient online submission

- Rigorous peer review

- Immediate publication on acceptance

- Open access: articles freely available online

- High visibility within the field

- Retaining the copyright to your article

Submit your next manuscript at $>$ springeropen.com 